\title{
MEMBANGUN BUDAYA LITERASI DALAM PEMBELAJARAN BAHASA INDONESIA MENGHADAPI ERA MEA
}

\author{
Heru Susanto \\ Program Studi Pendidikan Bahasa dan Sastra Indonesia, STKIP Singkawang \\ Email: anto_eru@yahoo.co.id
}

\begin{abstract}
Abstrak. Bahasa Indonesia merupakan bahasa resmi bangsa Indonesia. Saat ini keberadaan bahasa Indonesia mendapat tantangan yang serius baik itu tantangan internal maupun tantangan eksternal. Bahasa Indonesia yang seharusnya harus terus dilestarikan keberadaannya sekarang ini cenderung megalami pergeseran. Sikap kurang peduli dari seluruh pengguna bahasa menjadikan bahasa Indonesia tidak mendapat kedudukan yang pantas dikalangan penggunanya. Bahasa Indonesia justru hanya sebagai perlambang dalam kegiatan-kegiatan resmi saja. Bahasa Indonesia yang baik dan benar hanya sebagai slogan saja. Bahasa Indonesia yang diplintir dengan bahasa-bahasa lain menjadikan bahasa alay yang banyak digunakan kalangan muda untuk berkomunikasi, yang justru merekalah yang seharusnya melestarikan keberadaan bahasa Indonesia tersebut. Lebih parahnya lagi bahasa alay tersebut menjadikan sebuah keharusan untuk menunjukkan eksistensi mereka atau pengakuan diri mereka. Ditambah lagi ketika memasuki era Masyarakat Ekonomi ASEAN (MEA), keberadaan bahasa Indonesia akan mendapatkan tantangan kedua dengan banyaknya arus tenaga kerja asing yang akan berkerja di Indonesia. Hal ini jelas akan mengancam keberadaan bahasa Indonesia jika kita tidak mau berbenah mulai dari sekarang. Untuk bisa memperbaiki persoalan ini para akademisi, ahli bahasa, guru pendidikan bahasa Indonesia harus dapat memberikan contoh yang positif tentang penggunaan bahasa Indonesia yang sesuai dengan kaidah. Serta memberikan pengertian mengenai kedudukan bahasa Indonesia. Selain itu pemerintah pusat sebagai pembuat kebijakan juga harus merespon dengan cepat menanggapi persoalan ini. Bila perlu mengeluarkan kebijakan yang mengharuskan penggunaan bahasa dalam setiap komunikasi di lingkungan instansi pemerintah. Salah satu upaya dalam melestarikan bahasa Indonesia yaitu dengan budaya literasi dalam pembelajaran bahasa Indonesia, maka dengan budaya literasi masyarakat Indonesia akan mampu mempertahankan bahasa Indonesia ditengah-tengah tantangan baru pada era Masyarakat Ekonomi ASEAN (MEA).
\end{abstract}

Kata Kunci: Budaya Literasi, Bahasa Indonesia, MEA

\section{PENDAHULUAN}

Bahasa Indonesia lahir pada tanggal 28 Oktober 1928 yang dikenal dengan Sumpah Pemuda. Bahasa Indonesia pada masa itu dijadikan sebagai alat pemersatu dalam perjuangan untuk meraih kemerdekaan. Selain itu bahasa Indonesia mampu menggerakkan dan membangkitkan semangat para pemuda untuk bersama-sama lepas dari belenggu penjajahan. Sejak saat itu bahasa Indonesia dijadikan sebagai bahasa resmi bangsa Indonesia. Sebagai bahasa pemersatu, bahasa Indonesia mampu menjadi penghubung keanekaragaman suku yang yang ada di Indonesia. Sebagai jati diri bangsa bahasa Indonesia haruslah senantiasa dijaga, dirawat dan terus dikembangkan. Hal tersebut sejalan dengan pendapat [1] yang menyatakan bahwa sebagai salah satu sarana pembinaan jati diri bangsa, bahasa Indonesia senantiasa perlu dirawat dan dikembangkan.

Namun, saat ini bahasa Indonesia mulai mengalami pergeseran dikalangan pengguna bahasa di Indonesia, khususnya masyarakat Indonesia. Masyarakat Indonesia saat ini kurang menghargai bahasa Indonesia dengan sewajarnya. Penggunaan bahasa Indonesia dalam kehidupan bermasyarakat tidak lagi memperhatikan kaidah-kaidah yang semestinya. Pertanyaan yang muncul sekarang adalah apakah yang sudah dilakukan oleh pemangku kepentingan dalam situasi ini? Apa yang sudah dilakukan oleh para ahli bahasa, para akademisi, dan juga pemerintah untuk mengatasi persoalan ini, setidaknya agar fenomena ini tidak semakin parah. Peran para pemangku kepentingan mungkin sudah melakukan banyak hal untuk memberikan pemecahan terhadap persoalan ini berdasarkan kapasitas masing-masing. Namun, segala usaha yang telah dilakukan dirasa belum berdampak pada perubahan secara mendasar.

Belum lagi mulai tahun 2015 yang lalu kita menghadapi era MEA. Banyak masyarakat yang belum mengetahui secara menyeluruh tentang apa itu MEA. Selain itu apa kaitan MEA dengan bahasa Indonesia. Hal ini tentunya haruslah mendapatkan perhatian yang serius khususnya pemerintah melalui Departemen Pendidikan dan Kebudayaan. Kondisi MEA yang mengharuskan pemerintah kita membuka kran tenaga kerja asing untuk masuk ke Indonesia dengan mudah akan mengancam keberadaan bahasa Indonesia. Belum lagi ditambah persoalan masyarakat kita yang cenderung acuh terhadap penggunaan bahasa Indonesia secara baik dan benar. Masyarakat Ekonomi ASEAN (MEA) menjadi isu yang hangat diperbincangkan akhir-akhir ini. Banyak aspek yang akan terkena pengaruh dari diterapkannya MEA tersebut. Tentu dampak positif dan negatif harus siap dihadapi bangsa 
Indonesia. Terlebih dalam kaitannya dengan bahasa
persatuan, bahasa Indonesia. Tentu diterapkannya MEA memberikan dampak logis terhadap keberadaan bahasa Indonesia.

Persoalan tersebut tentunya harus mendapat perhatian yang serius dari seluruh elemen negara kita tidak hanya sebagai bahan diskusi tanpa ada aksi nyata. Persoalan inilah lahan bagi para ahli bahasa, akademisi, guru pendidikan bahasa Indonesia serta pemerintah yang berwenang membuat kebijakan dalam mengatasi persoalan ini. Salah satu cara yang dapat silakukan yaitu dengan menumbuhkan budaya literasi pada masyarakat Indonesia khususnya para pelajar. Cara ini secara otomatis akan memberikan gambaran yang baik tentang penggunaan bahasa Indonesia secara baik dan benar. Sehingga dengan begitu akan turut serta mengembangkan dan melestarikan bahasa Indonesia itu sendiri.

\section{PEMBAHASAN}

\section{Bahasa Indonesia}

Negara yang merdeka dan berdaulat dalam menjalankan roda pemerintahan pastilah memerlukan suatu bahasa yang resmi. Selain itu suatu negara yang merdeka juga pasti memiliki bahasa yang wajib digunakan oleh masyarakatnya untuk berkomunikasi. Sehingga walaupun orang yang berkomunikasi tersebut berasal dari daerah atau suku yang berbeda mereka akan tetap berkomunikasi menggunakan bahasa resmi tersebut, dengan begitu jalinan komunikasi akan tetap berjalan dengan baik. Bahasa yang digunakan sebagai bahasa pemersatu ini disebut sebagai bahasa negara ataupun bahasa nasional. Bahasa nasional dan bahasa negara di Indonesia adalah Bahasa Indonesia. Kedudukan bahasa Indonesia sebagai bahasa nasional tersebut sangatlah penting dan harus terpenuhi fungsinya. Jika ada salah satu yang tidak terpenuhi maka fungsi Bahasa Indonesia sebagai bahasa pemersatu akan pudar dan akan sirna. Menurut [2] tanpa adanya bahasa (termasuk bahasa Indonesia) iptek tidak dapat tumbuh dan berkembang. Selain itu bahasa Indonesia di dalam struktur budaya, ternyata memiliki kedudukan, fungsi, dan peran ganda, yaitu sebagai akar dan produk budaya yang sekaligus berfungsi sebagai sarana berfikir dan sarana pendukung pertumbuhan dan perkembangan ilmu pengetahuan dan teknologi. Di dalam kedudukannya sebagai bahasa negara, Bahasa Indonesia berfungsi sebagai a) bahasa resmi kenegaraan, b) bahasa pengantar dalam dunia pendidikan, c) alat perhubungan ditingkat nasional untuk kepentingan perencanaan dan pelaksanaan pembangunan, d) Alat pengembangan kebudayaan, ilmu pengetahuan dan teknologi [3]. Bahasa Indonesia sebagai sarana komunikasi yang efektif antar suku yang ada di Indonesia harus se nantiasa dijaga. Menurut [4] hal penting yang perlu dilakukan agar bahasa Indonesia mampu menjadi wahana komunikasi yang efektif adalah pencendekiaan dan pemerkayaan bahasa tersebut. Untuk itu, upaya peningkatan mutu rancang bangunnya atau tingkat kebakuan kaidahnya serta pemekaran kosa katanya perlu terus dilaksanakan.
Di tengah perkembangan bahasa Indonesia yang saat ini mulai dipelajari oleh negara lain, tanpa kita sadari eksistensi bahasa Indonesia saat ini sedang mengalami tantangan yang dapat mempengaruhi eksistensi bahasa Indonesia. Seperti yang diungkapkan [5] mengemukakan bahwa bahasa Indonesia mendapat bermacam-macam pengaruh dari luar, yaitu pengaruh dari bahasa asing dan bahasa daerah. Pengaruh pertama berasal dari internal pengguna bahasa Indonesia itu sendiri. Kalau kita cermati fenomena saat ini kalangan anak muda yang masuk dalam usia pelajar mereka menggunakan bahasa Indonesia kurang memperhatikan kaidah penggunaan bahasa yang semestinya. Bahasa dikalangan anak-anak muda yang cenderung alay dan mencampuradukan bahasa-bahasa lain dalam berkomunikasi menjadikan racun yang secara perlahan merusak bahasa Indonesia itu sendiri.

Penggunaan bahasa Indonesia yang sesuai kaidah sudah tidak lagi digunakan dikalangan anak-anak muda sekarang ini. Padahal mereka adalah generasi penerus bangsa yang sudah seharusnya menggunakan bahasa Indonesia yang susuai dengan kaidah. Lebih-lebih lagi mampu mengembangkan bahasa Indonesia sesuai dengan kebutuhan dan perkembangan zaman. Hal itu jauh dari yang semsetinya. Bahkan yang lebih parah lagi bahasa-bahasa alay yang digunakan tersebut cenderung dijadikan sebuah pengakuan diri bagi penggunanya. Pengaruh kedua berasal dari eksternal, yaitu pengaruh negatif dari bahasa asing. Pengaruh negatif dari bahasa asing seperti masuknya kosakata asing yang tanpa melalui proses pembentukan istilah dan penggunaan struktur kalimat yang sesuai dengan kaidah yang semestinya. Kedua ancaman tersebut menimbulkan bahasa baru yang kebih dikenal dengan bahasa alay atau bahasa gaul yang sering digunakan kalangan muda pada masyarakat kita.

\section{Budaya Literasi}

Literasi dapat diartikan sebagai kemampuan membaca dan kemampuan menulis atau dapat disebut dengan melek aksara atau keberaksaraan [6]. Seseorang dapat dapat dikatakan literat jika mereka sudah dapat memahami suatu hal karena telah memahami informasi sebagai hasil dari membaca yang tepat dan melaksanakan pemahamannya sesuai dengan apa yang dia serap. Penguasaan literasi dalam segala bentuk ilmu pengetahuan sangat diperlukan karena dengan begitu akan ikut serta mendorong kemajuan suatu bangsa. Literasi sebagai sebuah bentuk kegiatan untuk menafsirkan atau menginterpretasikan segala bentuk ilmu pengetahuan akan membangun manusia yang memiliki pengetahuan yang luas. Mengingat pentingnya apa itu literasi sepertinya hal ini bertolak belakang dengan apa yang terjadi pada masyarakat kita. Khususnya kalangan pelajar sepertinya kurang meminati budaya literasi. Padahal begitu besar manfaat literasi bagi kalangan pelajar untuk menambah ilmu yang mereka pelajari di sekolah.

Menumbuhkan budaya literasi dikalangan pelajar memang memerlukan kerja keras terutama pendidik sebagai ujung tombak dunia pendidikan. Pendidik dapat melakukan pembiasaan-pembiasaan membaca kepada peserta didik agar 
mereka terbiasa tanpa adanya tekanan atau paksaan. Menurut [7] kebiasaan adalah perbuatan yang dilakukan secara berulang-ulang tanpa adanya unsur paksaan. Menumbuhkan kebiasaan membaca pada kalangan pelajar bukan merupakan suatu yang alamiah melainkan hasil dari sebuah proses belajar yang dilakukan secara terus-menerus. Perkembangan kebiasaan melakukan kegiatan terutama kegiatan membaca merupakan proses belajar yang dipengaruhi oleh dua faktor yaitu faktor internal dan eksternal. [8] menyatakan bahwa dalam setiap proses belajar, kemampuan mendapatkan ketrampilan-ketrampilan baru tergantung dari dua faktor, yaitu faktor internal dalam hal ini kematangan individu dan ekternal seperti stimulasi dari lingkungan.

Budaya literasi akan mempengaruhi tingkat pengetahuan yang meliputi sistem ide atau gagasan yang dimiliki oleh manusia. Hasil dari budaya literasi tersebut akan menjadikan manusia akan siap dalam segala tantangan dalam permasalahan kehidupan sehari-hari. Dalam kaitannya dengan pendidikan indikator performa Budaya literasi pembelajaran Bahasa Indonesia yang diharapkan adalah pada akhir pendidikan setiap tingkatan peserta didik SD/MI dan SMP/MTs sekurang-kurangnya telah membaca 9 buku, sedangkan peserta didik SMA/MA sekurang-kurangnya telah membaca 15 buku sastra atau nonsastra. Ketentuan ini merupakan target minimal yang diharapkan dari pembelajaran bahasa Indonesia di sekolah-sekolah atau madrasah.

Ada beberapa faktor yang mempengaruhi kenapa begitu rendahnya budaya literasi dikalangan masyarakat kita khsusnya pelajar. Faktor yang paling menonjol yaitu rendahnya minat baca pada sebagai besar masyarakat Indonesia. Kemampuan membaca yang baik akan sangat mempengaruhi peningkatan mutu sumber daya manusia pada suatu bangsa. Karena dengan menumbuhkan minat baca pada sebagian besar masyarakat kita akan menjadikan manusia Indonesia cepat menyesuaikan dengan segala bentuk perkembangan zaman yang meliputi segala bentuk aspek kehidupan manusia.

\section{Masyarakat Ekonomi ASEAN (MEA)}

Pertumbuhan ekonomi suatu negara merupakan hal utama yang perlu dicapai karena setiap negara menginginkan adanya proses perubahan perekonomian yang lebih baik dan ini akan menjadi indikator keberhasilan pembangunan ekonomi suatu negara. Percepatan pertumbuhan ekonomi dilakukan mulai dari pembenahan internal kondisi perekonomian di suatu negara bahkan sampai melakukan kerjasama internasional dalam segala bidang untuk dapat memberikan kontribusi positif demi percepatan pertumbuhan ekonomi. Hal tersebut menjadi landasan penting terbentuknya Masyarakat Ekonomi ASEAN 2015 dengan tujuan yang baik. Adapun tujuan dibuatnya Ekonomi ASEAN 2015 yaitu untuk meningkatkan stabilitas perekonomian dikawasan ASEAN dengan dibentuknya kawasan ekonomi ASEAN 2015 ini diharapkan mampu mengatasi masalah-masalah dibidang ekonomi antarnegara ASEAN. Selain itu dibukanya perdagangan bebas dikawasan ASEAN diprediksi mampu mendorong hal positif bagi ekonomi Indonesia, pertama, mendorong pendapatan Negara melalui eksport dan impor. Kedua, membuka peluang industrialisasi baru di kawasan Indonesia. Ketiga, memperluas lapangan kerja profesional bagi generasi muda baru di Indonesia serta memberikan kesempatatn berkarir di ASEAN.

Masyarakat Ekonomi ASEAN (MEA) akan membentuk ASEAN sebagai pasar dan basis produksi tunggal. Langkah ini jelas akan membuat ASEAN lebih dinamis dan kompetitif. Langkah demikian disepakati Negara-negara anggota ASEAN untuk memperkuat pelaksanaan kegiatan baru yang ada inisiatif ekonomi, mempercepat integrasi regional di sektor-sektor prioritas, memfasilitasi pergerakan bisnis, tenaga kerja terampil dan bakat, dan memperkuat kelembagaan mekanisme ASEAN. Pembentukan pasar tunggal yang diistilahkan dengan Masyarakat Ekonomi ASEAN (MEA) ini nantinya memungkinkan satu negara menjual barang dan jasa dengan mudah ke negara-negara lain di seluruh Asia Tenggara sehingga kompetisi akan semakin ketat.

Pentingnya Masyarakat Ekonomi ASEAN tidak terlepas dari dampak positif dan manfaat dari diberlakukannya perdagangan bebas di wilayah regional Asia Tenggara tersebut. Mungkin saat ini dampak positifnya belum begitu terasa karena MEA baru saja diberlakukan yaitu pada tahun 2015, namun diharapkan manfaat besarnya akan terasa pada tahun-tahun selanjutnya. Dampak positif dari Masyarakat Ekonomi ASEAN itu sendiri antara lain yaitu a) masyarakat Ekonomi ASEAN akan mendorong arus investasi dari luar masuk ke dalam negeri yang akan menciptakan multiplier effect dalam berbagai sektor khususnya dalam bidang pembangunan ekonomi. b) kondisi pasar yang satu (pasar tunggal) membuat kemudahan dalam hal pembentukan kerjasama antara perusahaan-perusahaan diwilayah ASEAN sehingga akses terhadap bahan produksi semakin mudah. c) pasar Asia Tenggara merupakan pasar besar yang begitu potensial dan juga menjanjikan dengan luas wilayah sekitar 4,5 juta kilometer persegi dan jumlah penduduk yang mencapai 600 juta jiwa. d) MEA memberikan peluang kepada negara-negara anggota ASEAN dalam hal meningkatkan kecepatan perpindahan sumber daya manusia dan modal yang merupakan dua faktor produksi yang sangat penting. e) Khusus untuk bidang teknologi, diberlakukannya Masyarakat Ekonomi ASEAN ini menciptakan adanya transfer teknologi dari negara-negara maju ke negara-negara berkembang yang ada diwilayah Asia Tenggara.

[9] menjelaskan ketika MEA disepakati pada tahun 2007, hampir semua orang hanya berfokus pada huruf tengahnya saja, yakni "ekonomi”. Hal itu dimaklumi karena tingkat urgensinya bagi setiap negara di kawasan ASEAN. Bahasa (hanya) menjadi salah satu variabel pada tahapan implementasinya. Saat kita bersama akan memasuki gerbang MEA, mulai disadari bahwa peranan bahasa tidak kalah pentingnya dalam implementasi kesepakatan di atas. Muncul pertanyaan, bahasa komunikasi apa yang akan digunakan dalam pergaulan ASEAN dalam konteks MEA? Kegalauan ini bukan hanya milik bangsa Indonesia saja, namun pula bangsa ASEAN lainnya. Keberadaan Bahasa Inggris 
memang menjadi solusi cepat kegamangan tadi, apalagi dua dari anggota ASEAN merupakan bagian dari negara-negara persemakmuran (Commonwealth). Namun sejauh mana keefektifannya? Demikian banyak pertanyaan terkait bahasa dalam konteks ini. Untuk bangsa Indonesia hal ini menjadi tantangan yang besar karena Bahasa Indonesia merupakan bahasa yang paling banyak penuturnya. Apakah Bahasa Indonesia sudah siap menjadi bahasa ASEAN? Apakah cukup hanya berbasis sebagai penutur terbesar? Apakah pembelajaran Bahasa Indonesia di tanah air sudah dipersiapkan sebagai bahasa kawasan? Hal ini merupakan bentuk problematika era MEA. Ada hal yang positif berkenaan MEA seperti yang di ungkapkan oleh [10] yang menyampaikan bahwa hal positif yang berkaitan dengan penggunaan bahasa Indonesia adalah, kemungkinan bahasa Indonesia menjadi bahasa resmi ASEAN karena banyak masyarakat pengguna bahasa Indonesia yang serumpun dengan bahasa Melayu yang juga digunakan 3 negara lain, yaitu Malaysia, Singapura, dan Brunei Darussalam.

\section{SIMPULAN}

\section{Membangun Budaya Literasi Dalam Pembelajaran Bahasa Indonesia Dalam Menghadapi Era Mea}

Belajar suatu bahasa berarti kita juga akan mempelajari budaya suatu daerah. Berkaitan dengan bahasa Indonesia yang menjadi bahasa resmi bangsa Indonesia dan menjadi suatu ciri khas bangsa Indonesia, maka setiap orang yang mempelajarinya berarti juga akan mempelajari budaya bangsa Indonesia. Masyarakat Indonesia sebagai penduduk asli harus bangga dan mempunyai sikap yang jelas dalam menggunakan bahasa Indonesia dalam bersosialisasi, dengan begitu akan tumbuh penghargaan akan pentingnya nilai yang terkandung dalam bahasa Indonesia. hal tersebut sekaligus akan melestarikan bahasa Indonesia ditengah-tengah tantangan globalisasi yang semakin pesat.

Tujuan pembelajaran bahasa Indonesia adalah agar siswa memiliki kemampuan berbahasa Indonesia yang baik dan benar serta dapat menghayati bahasa dan sastra Indonesia sesuai dengan situasi dan tujuan berbahasa serta tingkat pengalaman siswa [11] Saat ini pembelajaran bahasa Indonesia di sekolah sudah mengarah pada pembelajaran berbasis pada teks. Pembelajaran berbasis pada teks ini secara langsung akan memaksa pembelajar baik siswa ataupun siapa saja yang belajar bahasa Indonesia akan membaca secara terus menerus. Persoalan yang muncul dari sistem pembelajaran bahasa Indonesia yang berbasis pada teks yaitu budaya membaca masyarakat kita khususnya pelajar sangat jauh dari harapan. Hal tersebut tidak hanya terjadi pada siswa, namun juga para pendidik yang kurang memiliki budaya membaca secara konsisten. Permasalahan lemahnya budaya membaca sebagian besar masyarakat khususnya kalangan pelajar akan berdampak pada terhambatnya tujuan pembelajaran yang berbasis pada teks tersebut. Harus ada langkah kongkret baik itu dari pemerintah melalui instansi terkait untuk menanggulangi masalah tersebut.
Pembelajaran bahasa Indonsia pada lembaga-lembaga pendidikan saat ini sebenarnya sudah mulai ditingkatkan. Namun kenyataan di lapangan belum dapat dirasakan keseluruh pelosok daerah. Ketersediaan buku-buku pelajaran masih terbatas bahkan pada daerah tertentu masih kekurangan buku-buku pelajaran. Menumbuhkan budaya literasi dalam pembelajaran bahasa Indonesia menjadi tugas para pendidik untuk bisa menggerakkan siswanya agar gemar membaca. Selain itu sebagai pendidik juga harus memberikan contoh dengan gemar membaca agar mampu memberikan pengetahuannya kepada siswanya dengan informasi-informasi yang baru. Menumbuhkan budaya literasi pada kalangan siswa setidaknya akan memberikan peningkatan mutu siswa, setidaknya akan menambah kosakata baru yang akan membantu siswa dalam memahami persoalan yang berkaitan dengan pelajaran di sekolah.

Selain itu peran pemerintah juga sangat diharapkan agar budaya literasi ini akan terwujud. Peran pemerintah dalam hal menumbuhkan budaya literasi dapat diwujudkan dengan berbagai bentuk, mulai dari kegiatan seminar-seminar yang dapat membangkitkan minat baca masyarakat Indonesia. Fasilitas-fasilitas yang menyediakan bahan-bahan bacaan juga harus dibagun dan dilengkapi secara merata agar dapat dirasakan seluruh daerah yang ada di Indonesia sebagai perwujudan peran pemerintah pada sektor pendidikan. Budaya literasi berkaitan erat dengan masa deopan bangsa, maka dari itu perlu perhatian yang serius dari pemerintah.

Harapan terbesar menumbuhkan budaya literasi pada kalangan masyarakat Indonesia yaitu untuk mempersiapkan kondisi sebaik mungkin dalam mengahadapi era MEA. Arus globalisasi yang begitu deras harus segera disikapi agar masyarakat kita tidak tertinggal dari negara lain terutama eksistensi bahasa Indonesia sebagai bahasa resmi bangsa kita. Kualitas suatu bangsa sangat ditentukan oleh kecerdasan dan pengetahuan yang dimiliki sumber daya manusia di dalamnya. Hal tersebut didapat dari seberapa besar ilmu pengetahuan yang didapat. Semakin banyak sumber daya manusia yang haus akan ilmu pengetahuan maka akan semakin berkualitas sumber daya manusia di dalamnya.Persiapan yang begitu matang tidak membuat kita akan pesimis lagi dalam mengahadpi era MEA salah satu caranya yaitu dengan menumbuhkan budaya literasi pada manusia Indonesia.

\section{DAFTAR PUSTAKA}

[1] Sedyawati, Edi. 1993. "Bahasa Indonesia dalam Pengembangan Kebudayaan Nasional," Makalah disajikan dalam Kongres Bahasa Indonesia VI. Jakarta, 28 Oktober-2 November 1993

[2] Nurhayati, Rokhmah. 2013. Pengaruh Globalisasi Terhadapa Eksistensi Bahasa Indonesia.http://sosbud.kompasiana.com/2012/09/25/pengaruhglobalisasi/terhadap-eksistensibahasa-indonesia.

[3] Arifin, E. Zaenal dan Tasai S. Amran. 2009. Cermat Berbahasa Indonesia Untuk Perguruan Tinggi. Jakarta: Akademika Pressindo.

[4] Suwandi, Sarwiji. 2004. "Pemantapan Peran Bahasa Kebangsaan sebagai Alat Kohesi Nasional" dalam Katharina Endriati Sukamto (Ed.) Menabur Benih Menuai Kasih, Persembahan Karya Bahasa, Sosial, dan Budaya untuk Anton M. Moeliono pada Ulang Tahunnya yang ke-75. Jakarta: Yayasan Obor Indonesia.

[5] Ngalim, Markhamah, Harun Joko Prayitno, dan Kun Kharisma. 2015. Integrasi Bahasa Inggris ke dalam Bahasa Indonesia Berbasis Teks 
Leksikon Promosi. Dalam Ali, A. Halim et., Mohd Azam Sulong, Mohd Hasan Abdullah, dan Ahmad Nizam Othman (Ed.), ICDETAH (International Conference on Develoment of Education, Environment, Tourism, Economics, Arts and Heritage. Universiti Sultan Idris. (Proceedings).

[6] Harras, Kholid A. 2011. "Mengembangkan Potensi Anak melalui Program Literasi Keluarga”, Jurnal Artikulati Vol. 10 No. 1.

[7] Kimbley, Gregory A. 1975. "Habit". Encyclopedia Americana.

[8] Gould, Toni S., 1991. Get Ready to Read: a Practical Guide for Teaching Young Children at Home and in School, New York : Walker Company

[9] Bahasa Indonesia pada Era MEA" Prosiding Seminar Nasional Optimalisasi Pembelajaran Bahasa Indonesia yang Berkualitas pada era MEA Universitas Muhamadiyah Surakarta. Surakarta.

[10] Pangemanan, Anastasia. 2015. "70 Tahun Berbahasa Indonesia: 'Merajut Kebhinekaan Menuju Bahasa Masyarakat Ekonomi ASEAN'. Makalah pada Seminar dan Lokakarya yang diselenggarakan Badan Bahasa pada 18 Agustus 2015.

[11] Akhadiah dkk. 1991. Pembelajaran Bahasa Indonesia. (www.lentera kecil.com. tanggal 20 Juli 2016 Pukul 11.00 WIB). 